\title{
A Method of Carbon Footprint Calculation for the Product Life Cycle
}

Qinyi Ma1 ${ }^{1}$, Qingchao Sun ${ }^{2}$, Yanqiu Liu ${ }^{1}$, Yajun Wang ${ }^{1}$, and Maojun Zhou ${ }^{1}$

${ }^{1}$ School of Mechanical Engineering and Automation, Dalian Polytechnic University, Dalian Liaoning 116034, China. Email: maqy@dlpu.edu.cn, liuyq@dlpu.edu.cn,wangyajun2004@hotmail.com,zhoumj@dlpu.edu.cn

${ }^{2}$ School of Mechanical Engineering, Dalian University of Technology, Dalian Liaoning 116024, China. E-mail: qingchao@dlut.edu.cn

This paper proposes a concept model for product life cycle to present the characteristics of material flow, energy flow and waste flow in a manufacture system. Furthermore, two energy consumption calculation methods are provided according to the different components of the manufacture system, one is e-p method based on the processes of the system, and the other is $\mathrm{e}-\mathrm{f} / \mathrm{s}$ method based on the functions and statuses of the system. Then a carbon footprint calculation method is proposed on the basis of the characteristics of material flow, energy flow and waste flow in a manufacture system, and the energy consumption calculation above. Input-output analysis is carried out to establish the carbon emission calculation information table.

Keywords: Carbon footprint, Emissions, Energy, Material, Input-output analysis

\section{Acknowledgements}

This work was financially supported by National Natural Science Foundation of China (No.51305051), the Liaoning Province Scientific Research Project Foundation (L2012189), and the Youth Foundation of Dalian Polytechnic University (QNJJ201211).

\section{References}

[1] MATTHEWS H.S., HENDRICKSON C.T., WEBER C.L. (2008). The importance of carbon footprint estimation boundaries. In: Environmental Science \& Technology, Vol. 42, No.16, pp. 5839-5842.

[2] SHAOJIAN W., CHUANGLIN F., HAITAO M., YANG W., JING Q. (2014). Spatial differences and multi-mechanism of carbon footprint based on GWR model in provincial China. In: Journal of Geographical Sciences, Vol. 24, No. 4, pp. 612-630.Springer-Verlag.

[3] SIMON P., JIRI K., IGOR B. (2008). Integrating waste and renewable energy to reduce the carbon footprint of locally integrated energy sectors. In: Energy, Vol.33, No.10, pp.1489-1497.

[4] CHRISTOPHER L. WEBER, AND H. SCOTT MATTHEWS. (2008). Quantifying the global and distributional aspects of American household carbon footprint. In: Ecological Economics, Vol.66, No.2-3, pp. 379-391.

[5] HUANG H, AMETA G. (2014). A Novel Pattern for Energy Estimation Framework and Tools to Compute Energy Consumption in Product Life-Cycle. In: Journal of Computing and Information Science in Engineering, Vol. 14, No. 1, pp. 011002. ASME Transactions. 